\title{
Effects of Repetitive Transcranial Magnetic Stimulation in the Rehabilitation of Communication and Deglutition Disorders: Systematic Review of Randomized Controlled Trials
}

\author{
Camila Dalbosco Gadenz Tais de Campos Moreira Dirce Maria Capobianco \\ Mauriceia Cassol \\ Graduate Program in Rehabilitation Sciences, Federal University of Health Sciences of Porto Alegre (UFCSPA), \\ Porto Alegre, Brazil
}

\section{Key Words}

Transcranial magnetic stimulation - Voice disorders . Speech disorders · Language disorders · Deglutition disorders

\begin{abstract}
Objective: To systematically review randomized controlled trials that evaluate the effects of repetitive transcranial magnetic stimulation (rTMS) on rehabilitation aspects related to communication and swallowing functions. Methods: A search was conducted on PubMed, Clinical Trials, Cochrane Library, and ASHA electronic databases. Studies were judged according to the eligibility criteria and analyzed by 2 independent and blinded researchers. Results: We analyzed 9 studies: 4 about aphasia, 3 about dysphagia, 1 about dysarthria in Parkinson's disease and 1 about linguistic deficits in Alzheimer's disease. All aphasia studies used low-frequency rTMS to stimulate Broca's homologous area. High-frequency rTMS was applied over the pharyngoesophageal cortex from the left and/or right hemisphere in the dysphagia studies and over the left dorsolateral prefrontal cortex in the Parkinson's and Alzheimer's studies. Two aphasia and all dysphagia studies showed a significant improvement of the disorder,
\end{abstract}

compared to the sham group. The other 2 studies related to aphasia found a benefit restricted to subgroups with a severe case or injury on the anterior portion of the language cortical area, respectively, whereas the Alzheimer's study demonstrated positive effects specific to auditory comprehension. There were no changes for vocal function in the Parkinson's study. Conclusion: The benefits of the technique and its applicability in neurogenic disorders related to communication and deglutition are still uncertain. Therefore, other randomized controlled trials are needed to clarify the optimal stimulation protocol for each disorder studied and its real effects.

(c) 2015 S. Karger AG, Basel

\section{Introduction}

Neurological diseases are important causes of death worldwide (12\% of the cases). They may also become a heavy burden for those who survive when some level of disability is caused. The neurological sequelae may include motor and/or cognitive aspects, which are behind many functions, such as communication and deglutition mechanisms. The result is an impact on the functionality

\section{KARGER 125}

(c) 2015 S. Karger AG, Base

1021-7762/15/0672-0097\$39.50/0

E-Mail karger@karger.com

www.karger.com/fpl
Camila Dalbosco Gadenz

Department of Speech-Language Pathology, UFCSPA

R. Sarmento Leite 245, Centro

Porto Alegre, RS 90050-170 (Brazil)

E-Mail camiladalbosco@ live.com 
of those affected, as well as on their quality of life $[1,2]$. The constant study of methods that aid in the rehabilitation of these disorders is crucial since, besides decreasing the need for care and health problems, they also lower death rates $[1,3]$.

Noninvasive transcortical stimulation such as repetitive transcranial magnetic stimulation (rTMS) has increasingly provided new insights to the neurological rehabilitation paradigm and its potentially therapeutic effects. Although it is still not understood completely, rTMS represents a promising perspective for neuroplasticity [4]. The technique produces a magnetic field in the brain, inducing an electrical current that excites inhibitory and excitatory cortical neurons [5]. Low-frequency rTMS causes an inhibitory effect on the targeted region, whereas high-frequency rTMS increases local brain activity. These mechanisms promote neuroplastic changes and can lead to clinical benefits $[2,6]$, including communication and deglutition disorders of individuals affected by neurological diseases [7-10].

Poststroke studies can use both low-frequency and high-frequency rTMS to promote the recovery of language functions [11]. Considering the most dominant language area, low-frequency rTMS can inhibit the right hemisphere (contralesional), which, in natural recovery, suppresses the affected left side via the corpus callosum, which some authors have called 'maladaptive neuroplasticity' [9, 12]. On the other hand, high-frequency rTMS can stimulate the recovery of perilesional areas related to language in the affected, left hemisphere [13]. For dysphagia, previous studies used high-frequency rTMS over the motor cortex but with divergence on the stimulated side $[10,14$, 15]. Deglutition representation is bilateral but asymmetric. Hence, when the stroke occurs in the dominant hemisphere, it causes dysphagia $[16,17]$. Nevertheless, the nonaffected side seems to restore the function $[10,14]$.

Furthermore, rTMS has been studied to improve motor and cognitive function in neurodegenerative disorders like Parkinson's (PD) and Alzheimer's (AD) disease $[7,8,18,19]$. Studies have explored the stimulation of the dorsolateral prefrontal cortex (DLPFC) because it seems to modulate the neurotransmitter systems and then improve clinical symptoms, including speech-language impairment in $\mathrm{AD}$ and $\mathrm{PD}[7,8,20]$. Other rTMS studies on PD have excited the motor cortex, since these patients have an impairment in cortical excitability that may be secondary to basal ganglia dysfunction, which may contribute to the PD symptoms [21].

A better understanding is required of the real benefits of rTMS on communication and swallowing deficits in neurological disease, including long-term effects, and the optimal stimulation parameters in each context $[22,23]$. Therefore, this paper sought to systematically review published randomized controlled trials that used rTMS, for the purpose of assessing the applicability of the technique and its effects on several communication and deglutition disorders.

\section{Methods}

The systematic review was carried out according to the guidelines of the PRISMA protocol for systematic reviews and metaanalysis [24]. It was registered in Prospero under protocol code CRD42014009997.

\section{Eligibility Criteria}

Inclusion Criteria. The review included randomized controlled trials with a sham group that assessed the effects of using rTMS in the communication and deglutition rehabilitation of individuals affected by neurological disorders.

Exclusion Criteria. Studies were excluded from this review if they (1) were not in accordance with the eligibility criteria, (2) duplicated other studies, (3) only presented the research protocol without results, (4) were reports of ongoing investigations, or (5) had a score of 2 or less according to the JADAD scale [25] (see below).

\section{Information Sources}

The following electronic databases were searched:

1 Medline (accessed through PubMed)

2 Cochrane Library (Central registry of controlled clinical trials)

3 Clinicaltrials.gov

4 ASHA (American Speech-Language-Hearing Association publications)

No restrictions were enforced regarding research date or language. The references of manually included articles were searched.

\section{Search Strategies}

The search included the MeSH Terms 'Voice Disorders', 'Speech Disorders', 'Language Disorders', and 'Deglutition Disorders' associated through the Boolean terms 'OR' and 'AND' with 'Transcranial Magnetic Stimulation'. We used the Randomized Controlled Trial filter in the PubMed search.

\section{Study Selection}

The titles and abstracts of the selected articles were assessed to include only those that met the eligibility criteria of the study. The abstracts that did not provide enough information were included in the full-text analysis. Two independent blinded reviewers (C.D.G. and T.d.C.M.) assessed the full texts of the articles to define the eligibility of the study. Disagreements were settled by consensus and, if needed, by a third reviewer (D.M.C.).

\section{Bias Risk among the Studies}

The methodological quality of the studies was assessed using the JADAD scale [25]. This scale features 5 questions regarding randomization, masking, and description of losses and exclusions
Gadenz/Moreira/Capobianco/Cassol 
Fig. 1. Selection of articles.

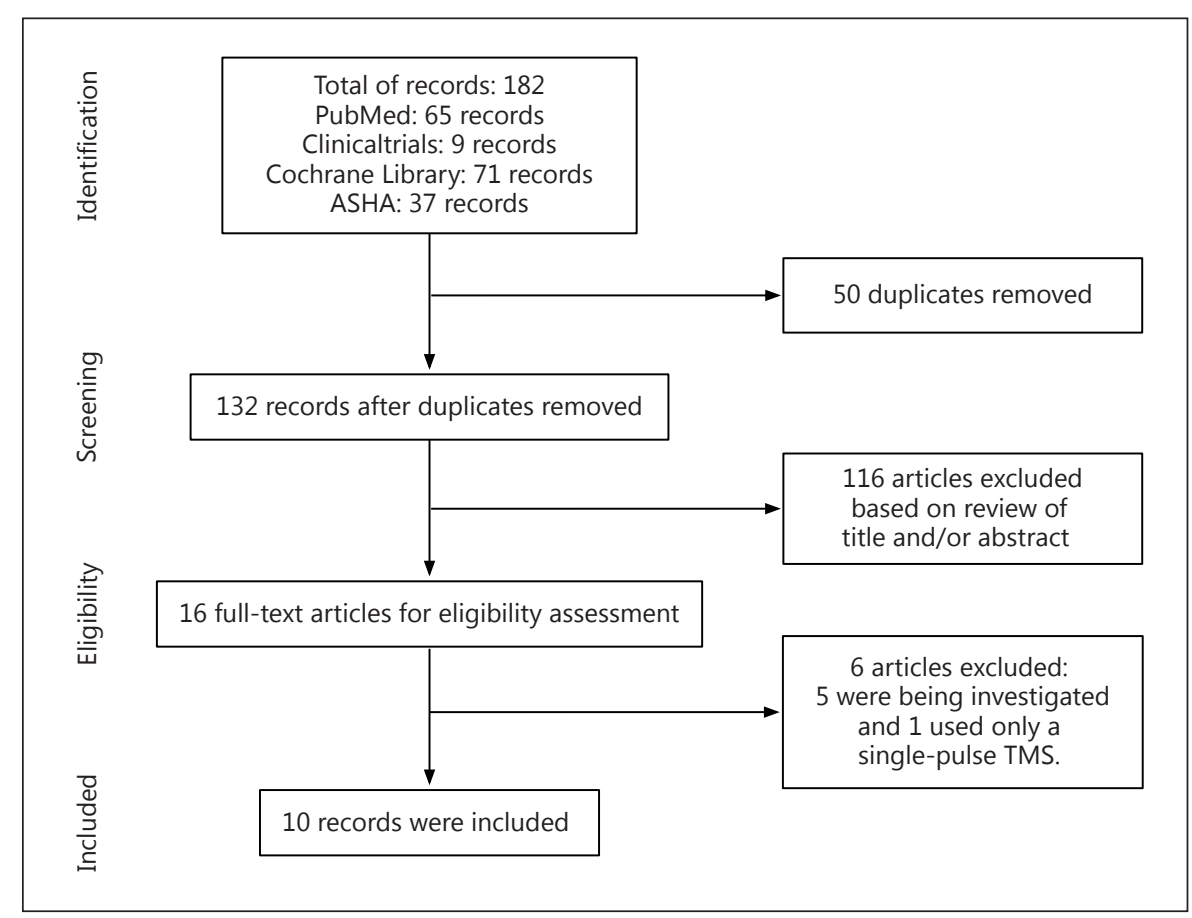

with the answers 'Yes' ( 1 point) and 'No' ( 0 points) for a maximum score of 5 points. Studies with a score equal to or below 2 are considered low-quality. The following criteria were considered for the assessment:

1 Randomization: The randomized sequence generation method is considered appropriate if it allowed each participant to have the same chances of receiving each intervention, guaranteeing the blinding of the randomization by the researcher. Sequence generation methods using birth date, admission date, hospital file number, or alternation between groups are considered inappropriate.

2 Double-blind masking: The study is considered double-blind if the term 'double-blind' was used. The method is considered appropriate if neither the person responsible for the patient's care nor the patient was able to identify the type of treatment received or, in the absence of this statement, if identical placebos or imitations were used.

3 Losses and exclusions: The participants who joined the study and did not complete the observation period or who were not included in the analysis are described. The number and reason of losses in each group is mentioned. If there were no losses, this is stated in the report. In case the losses are not described, a score of 0 is attributed to this item.

\section{Data Extraction and Analysis}

Two independent reviewers (C.D.G. and T.d.C.M.) extracted the following data: year, subject diagnosis, subject number, age, and gender stratified by group. Data regarding the technique such as duration, frequency, intensity, and coil type and position during stimulation were also obtained. Lastly, the assessment protocol of the main outcome, the major findings, the adverse effects, and dropouts were noted. These data were assessed qualitatively.

rTMS in Communication and Deglutition Disorders

\section{Results}

\section{Results of the Search}

After searching and screening 182 titles and abstracts, we selected 16 for full-text analysis according to the eligibility criteria; the selected articles were all in English (fig. 1). We included a total of 10 studies, 5 about aphasia $[9,11,26-28], 3$ related to dysphagia $[10,14,15], 1$ about hypokinetic dysarthria in PD [7], and another one regarding a language deficit that was a consequence of $\mathrm{AD}$ [8]. Posteriorly, an aphasia study [28] was excluded because of a low JADAD score [25]. We only included the first experiment of the study by Dias et al. [7], which was randomized, and the first stage of the study by Cotelli et al. [8], which compared the real rTMS group with the sham group. The final number of publications reviewed for this analysis was 9 .

\section{Characteristics of the Studies}

The characteristics of the studies are described in table 1 . The number of subjects per group ranged from 4 to 20 , and the average age of the participants in the studies ranged from 55.4 to 74.4 years. Studies that evaluated poststroke aphasia $[9,11,26,27]$ included right-handed patients with an injury in the left hemisphere, predominantly ischemic, except in the study by Weiduschat et al. [9], which also included participants with hemorrhagic 
Table 1. Study characteristics

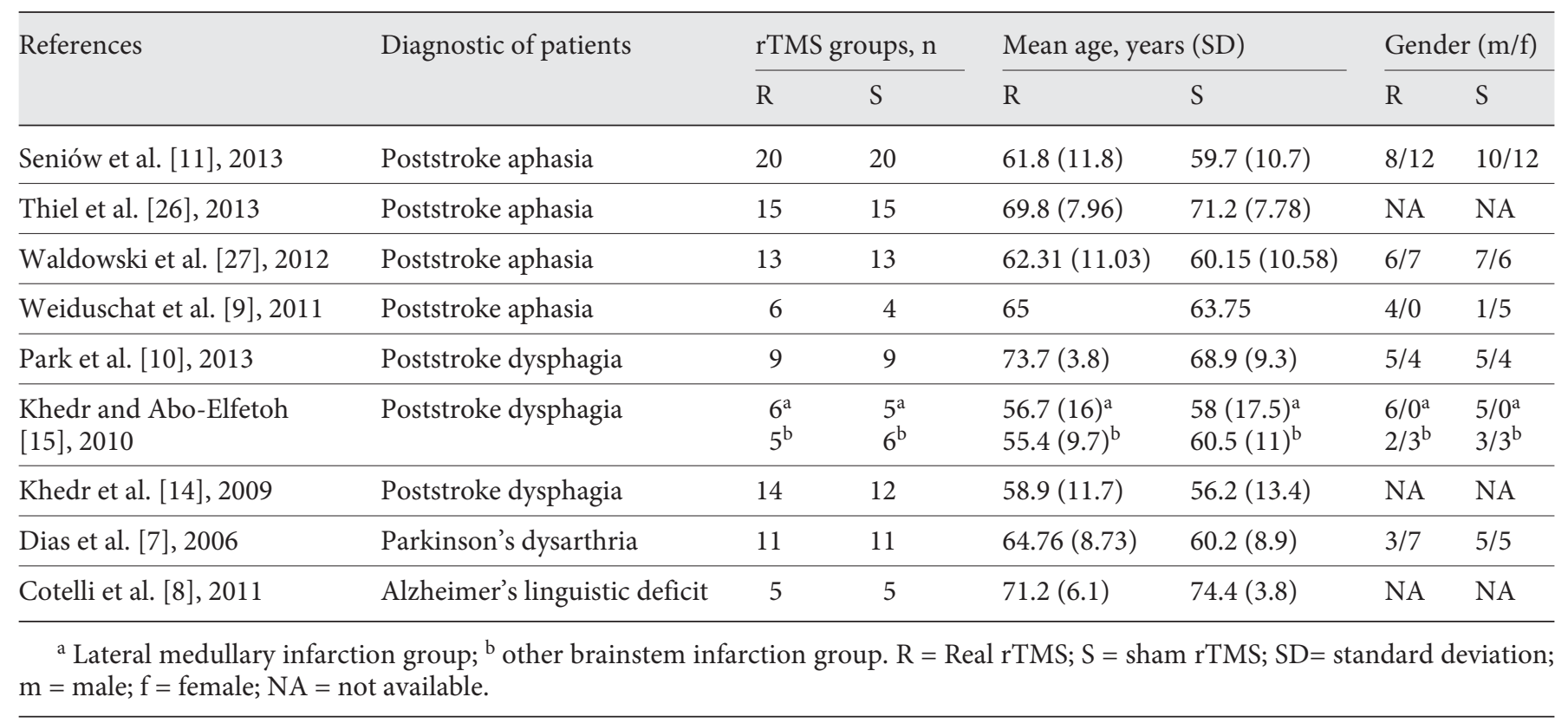

lesions. All patients were in the subacute phase and had different aphasic types. Dysphagia studies $[10,14,15]$ included participants with unilateral stroke on the right or left side. All participants had an ischemic injury, except for some individuals in the study by Park et al. [10] with hemorrhagic lesions. The patients were in the acute or subacute phase.

The participants of the study by Cotelli et al. [8] were diagnosed as having probable moderate $\mathrm{AD}$, according to criteria available from the National Institute of Neurological and Communicative Disorders and StrokeAlzheimer's Disease and Related Disorders Association (NINCDS-ADRDA). The patients had been on a stable dose of cholinesterase inhibitor (donepezil or rivastigmine) for at least 6 months prior to the onset of the study. The study by Dias et al. [7] included participants diagnosed with idiopathic PD according to the United Kingdom Parkinson's Disease Society Brain Bank criteria and were moderately to severely affected. The mean duration of disease was 7.8 years, and the mean L-dopa use was $555.0 \mathrm{mg}$.

\section{Protocol for Stimulation and Technique Effects}

The aphasia studies applied low-frequency rTMS over the homologous Broca's area (contralesional) $[9,11,26$, 27], whereas the dysphagia studies applied high-frequency rTMS over motor cortex areas related to deglutition
$[10,14,15]$. For neurodegenerative diseases, studies also used a high-frequency parameter, but with the coil positioned over the left DLPFC $[6,8]$. The number of stimulation sessions ranged from 5 to 15 , and they were performed daily, except on weekends. Participants of aphasia studies went through speech therapy for $45 \mathrm{~min}$ immediately after each simulation. The activities were chosen to activate the dominant hemisphere for language $[9,11,26$, 27]. All studies used validated protocols to evaluate each specific disorder.

The results were heterogeneous and limited. Compared with the sham group, 5 studies demonstrated positive results on clinical improvement of the participants [9, $10,14,15,26], 2$ showed a beneficial effect restricted to specific conditions $[11,27]$, while a third one evidenced it during a subtest [8]. One study did not ascertain improvement on vocal function of individuals suffering from PD [7].

Seven studies reported that no serious adverse effects such as seizures occurred [7-11,26,27], even though discomfort was identified in the study by Weiduschat et al. [9], which required reduction of stimulation intensity in 2 participants. Four studies reported exclusions or dropouts but none related to the use of rTMS $[9,11,15,26]$. The main reasons included lack of tolerance for the positron emission tomography or magnetic resonance scanner $[9,26]$, defect in the rTMS equipment $[9,26]$, death 
Table 2. Detailed summary of studies included in the current analysis

\begin{tabular}{|c|c|c|c|c|c|c|}
\hline \multirow[t]{2}{*}{ References } & \multicolumn{2}{|l|}{ rTMS } & \multirow{2}{*}{$\begin{array}{l}\text { Evaluation } \\
\text { protocol of the } \\
\text { primary outcome }\end{array}$} & \multirow[t]{2}{*}{ Major findings } & \multirow{2}{*}{$\begin{array}{l}\text { Serious } \\
\text { adverse } \\
\text { effects }\end{array}$} & Dropou \\
\hline & $\begin{array}{ll}\text { frequency, intensity, stimulus duration/ coil type } \\
\mathrm{Hz} & \% \mathrm{RMT} \text { No. of sessions }\end{array}$ & stimulation site & & & & $\mathrm{R}$ \\
\hline
\end{tabular}

\begin{tabular}{|c|c|c|c|c|c|c|}
\hline \multicolumn{7}{|l|}{ Aphasia } \\
\hline $\begin{array}{l}\text { Seniów } \\
\text { et al. [11], } \\
2013\end{array}$ & 1 & 90 & $\begin{array}{l}30 \text { min } \\
\text { per day/ } \\
15 \text { sessions }\end{array}$ & $\begin{array}{l}\text { Figure- } \\
\text { of- } \\
\text { eight }\end{array}$ & $\begin{array}{l}\text { Broca's area } \\
\text { homologue } \\
\text { (contralesional) }\end{array}$ & $\begin{array}{l}\text { The Polish } \\
\text { version of the } \\
\text { BDAE }\end{array}$ \\
\hline
\end{tabular}

\begin{tabular}{|c|c|c|c|c|c|c|}
\hline $\begin{array}{l}\text { Thiel } \\
\text { et al. [26], } \\
2013\end{array}$ & 1 & 90 & $\begin{array}{l}20 \text { min } \\
\text { per day/ } \\
10 \text { sessions }\end{array}$ & $\begin{array}{l}\text { Figure- } \\
\text { of- } \\
\text { eight }\end{array}$ & $\begin{array}{l}\text { Broca's area } \\
\text { homologue } \\
\text { (contralesional) }\end{array}$ & $\begin{array}{l}\text { The German } \\
\text { version of the } \\
\text { AAT }\end{array}$ \\
\hline $\begin{array}{l}\text { Waldowski } \\
\text { et al. [27], } \\
2012\end{array}$ & 1 & 90 & $\begin{array}{l}30 \text { min } \\
\text { per day/ } \\
15 \text { sessions }\end{array}$ & $\begin{array}{l}\text { Figure- } \\
\text { of- } \\
\text { eight }\end{array}$ & $\begin{array}{l}\text { Broca's area } \\
\text { homologue } \\
\text { (contralesional) }\end{array}$ & $\begin{array}{l}\text { 1) CPNT } \\
\text { 2) ASRS of the } \\
\text { Polish version of } \\
\text { the BDAE }\end{array}$ \\
\hline
\end{tabular}

\begin{tabular}{|c|c|c|c|c|c|c|c|c|c|c|}
\hline & & & & & & 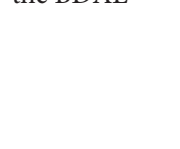 & $\begin{array}{l}\text { the language area compared } \\
\text { with sham group in the } \\
\text { follow-up, } 15 \text { weeks after the } \\
\text { end of the treatment }\end{array}$ & & & \\
\hline $\begin{array}{l}\text { Weiduschat } \\
\text { et al. [9], } \\
2011\end{array}$ & 1 & 90 & $\begin{array}{l}20 \text { min } \\
\text { per day/ } \\
8-10 \text { sessions }\end{array}$ & $\begin{array}{l}\text { Figure- } \\
\text { of- } \\
\text { eight }\end{array}$ & $\begin{array}{l}\text { Broca's area } \\
\text { homologue } \\
\text { (contralesional) }\end{array}$ & $\begin{array}{l}\text { The German } \\
\text { version of the } \\
\text { AAT }\end{array}$ & $\begin{array}{l}\text { There was an overall } \\
\text { improvement shown by total } \\
\text { AAT score, but not in the } \\
\text { subtests compared with sham } \\
\text { group }\end{array}$ & $\mathrm{No}$ & 1 & 3 \\
\hline
\end{tabular}

\begin{tabular}{llllll}
\hline $\begin{array}{l}\text { Dysphagia } \\
\text { Park }\end{array}$ & 5 & 90 & 10 min & $\begin{array}{l}\text { Figure- } \\
\text { of- }\end{array}$ & $\begin{array}{l}\text { Pharyngeal } \\
\text { motor cortex } \\
\text { et al. [10], }\end{array}$ \\
2013 & & $\begin{array}{l}\text { per day/ } \\
10 \text { sessions }\end{array}$ & $\begin{array}{l}\text { eight } \\
\text { (contralesional) }\end{array}$
\end{tabular}

$\begin{array}{llll}\text { Improvement of the repetition } & \text { No } & 1 & 1 \\ \text { function was restricted to } & & & \end{array}$

rTMS subgroup with severely

aphasic patients compared to

sham group in the follow-up,

15 weeks after the end of the

treatment

Overall improvement shown No $\quad 2 \quad 4$

by total AAT score and

naming function subtest

compared with sham group

Improvement of the naming No $\quad \begin{array}{lll}\text { No } & 0\end{array}$

reaction time restricted to

rTMS subgroup with a lesion

including the anterior part of

the language area compared

with sham group in the

follow-up, 15 weeks after the

There was significant

improvement of the VDS and

No $0 \quad 0$

PAS compared with sham

group. This effect was

maintained after 2 weeks.

When divided in 2

subcategories, the oral and

pharyngeal phase, only the latter showed significant betterment. In addition, the prevalence of aspiration and pharyngeal residues was also reduced

\begin{tabular}{|c|c|c|c|c|c|c|c|c|c|c|}
\hline $\begin{array}{l}\text { Khedr and } \\
\text { Abo-Elfetoh } \\
\text { [15], } 2010\end{array}$ & 3 & 130 & $\begin{array}{l}10 \mathrm{~min} \\
\text { per day/ } \\
5 \text { sessions }\end{array}$ & $\begin{array}{l}\text { Figure- } \\
\text { of- } \\
\text { eight }\end{array}$ & $\begin{array}{l}\text { Esophageal } \\
\text { motor cortex } \\
\text { (ipsi- and } \\
\text { contralesional) }\end{array}$ & $\begin{array}{l}\text { Dysphagia Rating } \\
\text { Scale }\end{array}$ & $\begin{array}{l}\text { Real rTMS significantly } \\
\text { improved dysphagia in both } \\
\text { LMI and OBI groups } \\
\text { compared with sham group. } \\
\text { The betterment was } \\
\text { maintained over } 2 \text { months of } \\
\text { follow-up }\end{array}$ & NA & 0 & 2 \\
\hline $\begin{array}{l}\text { Khedr } \\
\text { et al. [14], } \\
2009\end{array}$ & 3 & 120 & $\begin{array}{l}10 \mathrm{~min} \\
\text { per day/ } \\
5 \text { sessions }\end{array}$ & $\begin{array}{l}\text { Figure- } \\
\text { of- } \\
\text { eight }\end{array}$ & $\begin{array}{l}\text { Esophageal } \\
\text { motor cortex } \\
\text { (contralesional) }\end{array}$ & $\begin{array}{l}\text { Dysphagia Rating } \\
\text { Scale }\end{array}$ & $\begin{array}{l}\text { Real rTMS significantly } \\
\text { improved dysphagia } \\
\text { compared with sham group, } \\
\text { which was maintained over } \\
2 \text { months of follow-up }\end{array}$ & NA & NA & NA \\
\hline
\end{tabular}


Table 2 (continued)

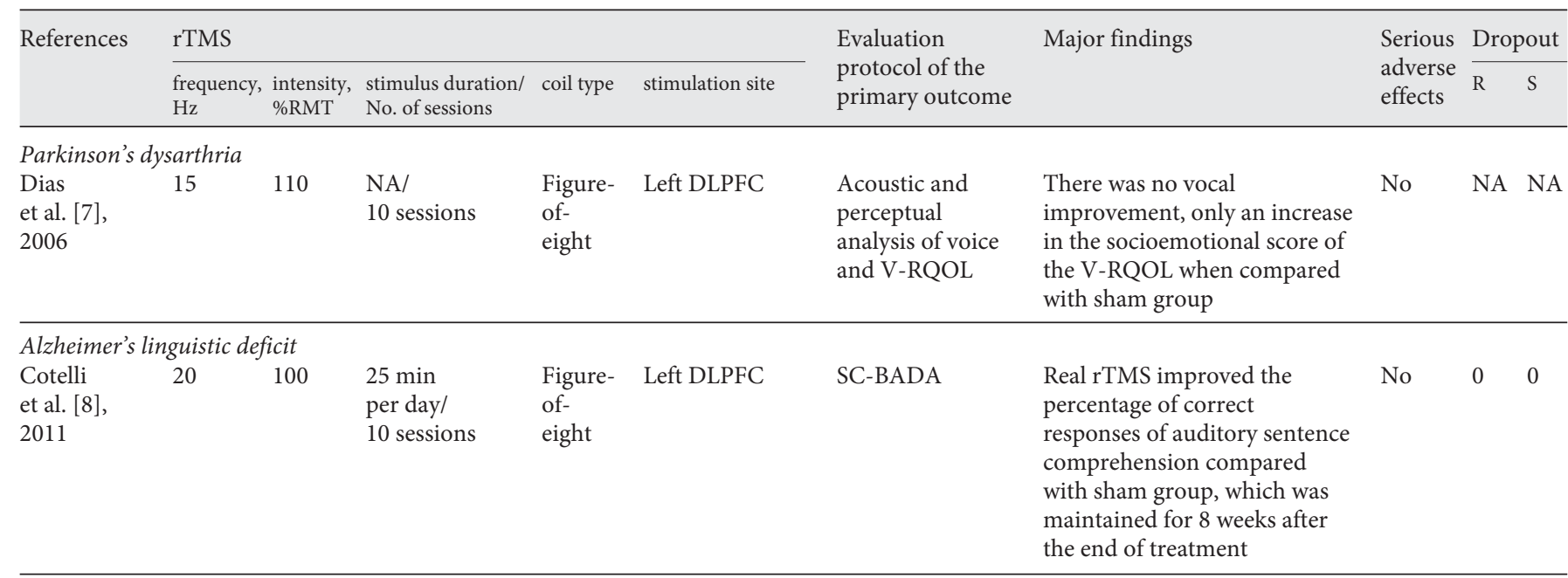

NA = Not available; RMT = resting motor threshold; BDAE = Boston Diagnostic Aphasia Examination; AAT = Aachen Aphasia Test; CPNT = Computerized Picture Naming Test; ASRS = Aphasia Severity Rating Scale; VDS = Videofluoroscopic dysphagia scale; PAS = Penetration-Aspiration Scale; V-RQOL = Voice-Related Quality of Life Questionnaire; SC-BADA = Battery for Analysis of Aphasic Deficits; LMI = lateral medullary infarction; OBI = other brainstem infarction.

Table 3. Risk of bias of included studies by the JADAD scale

\begin{tabular}{|c|c|c|c|c|c|c|}
\hline References & $\begin{array}{l}\text { Was the study } \\
\text { described as } \\
\text { randomized? }\end{array}$ & $\begin{array}{l}\text { Was the method } \\
\text { of randomization } \\
\text { appropriate? }\end{array}$ & $\begin{array}{l}\text { Was the study } \\
\text { described as } \\
\text { double-blind? }\end{array}$ & $\begin{array}{l}\text { Was the method } \\
\text { of double-blinding } \\
\text { appropriate? }\end{array}$ & $\begin{array}{l}\text { Was there a } \\
\text { description of with- } \\
\text { drawals and dropouts? }\end{array}$ & Score \\
\hline Thiel et al. [26], 2013 & Yes & No & Yes & No & Yes & 3 \\
\hline Waldowski et al. [27], 2012 & Yes & Yes & Yes & No & Yes & 4 \\
\hline Park et al. [10], 2013 & Yes & Yes & Yes & No & Yes & 4 \\
\hline Khedr and Abo-Elfetoh [15], 2010 & Yes & No & Yes & No & Yes & 3 \\
\hline Khedr et al. [14], 2009 & Yes & Yes & Yes & No & No & 3 \\
\hline Dias et al. [7], 2006 & Yes & Yes & Yes & No & No & 3 \\
\hline
\end{tabular}

of a participant [15], spontaneous improvement of the disorder before stimulation [9], or simply the withdrawal of a participant [11]. The summary details of the protocol for stimulation and effects of rTMS are presented in table 2 .

\section{Bias Risk among the Studies}

According to the JADAD scale [25] (table 3), only 1 study had a low quality and was therefore excluded from the analysis [28]. Three studies had a score reduction due to a lack of information on the randomization method $[8$, $15,26]$, and 2 did not report losses and exclusions $[7,14]$. Only 5 studies were described as double-blind [7, 9-11, 26]. However, other studies also carried out the blinding of the evaluator of the main outcome and of the participants according to the allocated group. Therefore, although they have not been termed as double-blind, we also considered adding 1 point to these cases. None of the 
studies blinded the investigator responsible for the rTMS management.

The studies used different types of sham to blind participants, such as changing the target area to midline vertex with the same rTMS parameters of stimulation $[9,26]$, tilting the real coil by 90 degrees $[10,14,15]$ and using a Magstim sham coil [11,27], Dantec sham coil [7], or a real electromagnetic placebo device for sham [8]. Two studies confirmed that the physical sensations produced by real and sham stimulations were slightly different. But since the individuals had never experienced rTMS, they would not know what kind of stimulation they had been subjected to $[11,27]$. Two other studies also reported that it was the participants' first experience with rTMS, even though they had undergone single-pulse TMS previously in order to register the resting motor threshold. This was necessary to orient the participants to the lower stimulation intensity that would be used in rTMS therapy and that they would not experience muscle twitching during the stimulation $[14,15]$. However, the success of blinding was not recorded in any study.

\section{Discussion}

This systematic review evaluated 9 randomized controlled trials that assessed the effects of rTMS for communication and swallowing disorders due to neurological diseases. The oldest study was the one by Dias et al. [7], which aimed to determine the effects of vocal function in PD after the application of rTMS over the left DLPFC. Although there were no benefits to the improvement of the voice, an increase in the socioemotional score of the Voice-Related Quality of Life Questionnaire was noticed. It is known that the DLPFC has connectivity with several cortical and subcortical areas and can modulate dopamine release in the basal ganglia [20]. However, there is also speculation that dopamine may not be effective for hypokinetic dysarthria improvement because there are often unsatisfactory results of pharmacological and surgical treatments for voice deficits in PD [7]. Some studies that have stimulated the orofacial cortex (rather than DLPFC) have shown more effective results for voice production in $\operatorname{PD}[7,18]$.

Cotelli et al. [8], who evaluated rTMS effects on linguistic aspects in $\mathrm{AD}$, used the same targeted area stimulation, and the results showed a significant increase in the percentage of correct answers to auditory comprehension of sentences. The authors suggested that the facilitation of DLPFC seemed to be specific to the language domain and had a nonspecific effect on cognitive processing $[8$,
$19,20]$. Indeed, the rTMS in the DLPFC seems to improve naming function on both $\mathrm{AD}$ and $\mathrm{PD}$ [29], although neurophysiological mechanisms subjacent to rTMS remain essentially unknown [8].

The majority of the studies evaluated the technique effects for poststroke patients, 3 with dysphagia and 4 with aphasia. The first group obtained an overall improvement of deglutition $[10,14,15]$ and a reduction of penetrationaspiration episodes [10]. The contralesional stimulation might increase the cortical excitability of the unaffected hemisphere, which enhanced stimulation of bulbar motor neuron projections to the pharynx and thus facilitated the swallowing function $[10,30]$. In the study by Khedr and Abo-Elfetoh [15], in which the participants had been diagnosed with lateral medullary syndrome or any other brainstem infarction, the authors suggested that the remaining intact ipsilateral premotor neurons and the contralateral center in medulla oblongata might also assume the function and improve dysphagia.

All aphasia studies used the same protocol, but with controversial results. Whereas the studies by Weiduschat et al. [9] and Thiel et al. [26] showed a significant improvement on aphasia posttreatment, the studies by Seniów et al. [11] and Waldowski et al. [27] showed improvement only in specific conditions, mainly during follow-up. The improvement was seen in severe patients or those with a lesion on the anterior portion of the area responsible for language. The main improvement reported was found in previous studies, and it seems to be related to the stimulation of Broca's area [9, 26, 31]. Moreover, severe patients have a greater imbalance between the hemispheres and can profit to a greater extent from contralesional inhibition [11]. The uncertain effectiveness of the protocol for stimulation suggested some speculation $[9,11,26,27]:$ the absence of comprehension improvement might be due to the fact that this function is related to Wernicke's lobe; the samples may have been too small to produce the statistical power to show a difference; the use of different protocols of outcome evaluation, the presence of participants with fluent and nonfluent aphasia or with different volumes of infarction may have contributed to controversial results; the lack of precision on the targeted stimulation area might have altered effects since the pars triangularis unlike the pars opercularis of Broca's area improves naming function, as shown in the study by Naeser et al. [31] with chronic aphasic patients. Speech therapy, when performed immediately after rTMS stimulation, used the increase of cortical excitability caused by the technique to excite the reorganization of language networks in the affected hemisphere $[9,11,26,27]$. 
No serious adverse events were reported, showing that rTMS can be safe, especially in poststroke individuals. The stimulation of the contralesional hemisphere seems to reduce the risk of seizures. However, a slight headache and muscle spasms at the stimulation site may occur, as shown in the study by Weiduschat et al. [9, see also 23$]$ in which stimulation intensity had to be reduced.

The risk of bias as evaluated by the JADAD scale [25] indicated that most studies had good methodological quality, although some studies did not report the randomization method or describe losses and exclusions. Furthermore, none reported the success of blinding. rTMS produced sounds and local sensations which demand an effective sham to achieve adequate blinding of participants and avoid placebo effects, but there was no consensus about a standard protocol for this condition. In addition, the need of someone trained to manage the technique does not allow blinding to the type of stimulation, except for pre- and postintervention assessments [6]. More careful study designs, with randomization and blinding, as well as a more effective sham is an important factor, since the effects of the technique depend directly on the parameters used but are also potentially impacted by methodological aspects [32].

There are few randomized controlled trials on the use of rTMS for communication and deglutition deficits consequent to neurogenic disorders, and further investigations are needed to expand the knowledge about the use of the technique in these contexts. Studies comparing real effects with sham, evaluating short- and long-term effects, as well as identifying the subjacent mechanisms for these changes can advance research about this new therapeutic approach and constantly upgrade its future clinical use in neurological rehabilitation. We also suggest inves- tigation of simultaneous speech therapy or a program based on exercises for deglutition along with rTMS, because it could maximize the effects of the technique. In addition, new application methods and the employment of equipment in conjunction with functional imaging techniques can also be used to ensure more effective and reliable results.

\section{Conclusion}

Although rTMS is a promising technique as a therapeutic method, further randomized controlled trials are necessary to define its applicability in rehabilitation disorders such as aphasia, poststroke dysphagia, and especially in communication and deglutition disorders in neurodegenerative diseases. In addition, this alternative approach should be more profoundly investigated, because its clinical use could contribute to pharmacological and classical nonpharmacological treatments for the betterment of patients diagnosed with neurological diseases.

\section{Acknowledgement}

This study is part of a dissertation developed in the Graduate Program in Rehabilitation Sciences of the Federal University of Health Sciences of Porto Alegre. The authors thank the professors of the program and the staff who provided the basis of this knowledge and the support required to develop this study.

\section{Disclosure Statement}

The authors declare that they have no conflict of interest.

\section{References}

1 Neurological Disorders: Public Health Challenges World Health Organization, 2006.

2 Brewer L, Horgan F, Hickey a, Williams D: Stroke rehabilitation: recent advances and future therapies. QJM 2013;106:11-25.

3 Von Campenhausen S, Winter Y, Rodrigues e Silva A, Sampaio C, Ruzicka E, Barone P, et al: Costs of illness and care in Parkinson's disease: an evaluation in six countries. Eur Neuropsychopharmacol 2011;21:180-191.

4 Kobayashi M, Pascual-Leone A: Transcranial magnetic stimulation in neurology. Lancet Neurol 2003;2:145-156.

5 Hamilton RH, Chrysikou EG, Coslett B: Mechanisms of aphasia recovery after stroke and the role of noninvasive brain stimulation. Brain Lang 2011;118:40-50.

6 Rossi S, Hallett M, Rossini PM, Pascual-Leone A: Safety, ethical considerations, and application guidelines for the use of transcranial magnetic stimulation in clinical practice and research. Clin Neurophysiol 2009;120:20082039.

7 Dias AE, Barbosa ER, Coracini K, Maia F, Marcolin MA, Fregni F: Effects of repetitive transcranial magnetic stimulation on voice and speech in Parkinson's disease. Acta Neurol Scand 2006;113:92-99.

8 Cotelli M, Calabria M, Manenti R, Rosini S, Zanetti O, Cappa SF, et al: Improved language performance in Alzheimer disease following brain stimulation. J Neurol Neurosurg Psychiatry 2011;82:794-797.

9 Weiduschat N, Thiel A, Rubi-Fessen I, Hartmann A, Kessler J, Merl P, et al: Effects of repetitive transcranial magnetic stimulation in aphasic stroke: a randomized controlled pilot study. Stroke 2011;42:409415.

10 Park J-W, Oh J-C, Lee J-W, Yeo J-S, Ryu KH: The effect of $5 \mathrm{~Hz}$ high-frequency rTMS over contralesional pharyngeal motor cortex in post-stroke oropharyngeal dysphagia: a randomized controlled study. Neurogastroenterol Motil 2013;25:324-e250. 
11 Seniów J, Waldowski K, Leśniak M, Iwański S, Czepiel W, Członkowska A: Transcranial magnetic stimulation combined with speech and language training in early aphasia rehabilitation: a randomized double-blind controlled pilot study. Top Stroke Rehabil 2013; 20:250-261.

12 Naeser MA, Martin PI, Nicholas M, Baker EH, Seekins H, Kobayashi M, et al: Improved picture naming in chronic aphasia after TMS to part of right Broca's area: an open-protocol study. Brain Lang 2005;93:95-105.

13 Holland R, Leff AP, Josephs O, Galea JM, Desikan M, Price CJ, et al: Speech facilitation by left inferior frontal cortex stimulation. Curr Biol 2011;21:1403-1407.

14 Khedr EM, Abo-Elfetoh N, Rothwell JC: Treatment of post-stroke dysphagia with repetitive transcranial magnetic stimulation. Acta Neurol Scand 2009;119:155-161.

15 Khedr EM, Abo-Elfetoh N: Therapeutic role of rTMS on recovery of dysphagia in patients with lateral medullary syndrome and brainstem infarction. J Neurol Neurosurg Psychiatry 2010;81:495-499.

16 Hamdy S, Aziz Q, Rothwell JC, Crone R, Hughes D, Tallis RC, et al: Explaining oropharyngeal dysphagia after unilateral hemispheric stroke. Lancet 1997;350:686-692.

17 Hamdy S, Aziz Q, Rothwell JC, et al: Recovery of swallowing after dysphagic stroke relates to functional reorganization in the intact motor cortex. Gastroenterology 1998;115:11041112.

18 Eliasova I, Mekyska J, Kostalova M, Marecek R, Smekal Z, Rektorova I: Acoustic evaluation of short-term effects of repetitive transcranial magnetic stimulation on motor aspects of speech in Parkinson's disease. J Neural Transm 2013;120:597-605.
19 Cotelli M, Manenti R, Cappa SF, Zanetti O, Miniussi C: Transcranial magnetic stimulation improves naming in Alzheimer disease patients at different stages of cognitive decline. Eur J Neurol 2008;15:1286-1292.

20 Ahmed MA, Darwish ES, Khedr EM, El Serogy YM, Ali AM: Effects of low versus high frequencies of repetitive transcranial magnetic stimulation on cognitive function and cortical excitability in Alzheimer's dementia. J Neurol 2012;259:83-92.

21 Lefaucheur JP: Motor cortex dysfunction revealed by cortical excitability studies in Parkinson's disease: influence of antiparkinsonian treatment and cortical stimulation. Clin Neurophysiol 2005;116:244-253.

22 Edwards MJ, Talelli P, Rothwell JC: Clinical applications of transcranial magnetic stimulation in patients with movement disorders. Lancet Neurol 2008;7:827-840.

23 Araújo HA, Iglesio RF, Correia GS de C, Fernandes DTRM, Galhardoni R, Teixeira MJ, et al: Transcranial magnetic stimulation and clinical applicability: perspectives in neuropsychiatric therapeutics. Rev Med (São Paulo) 2011;90:3-14.

24 Moher D, Liberati A, Tetzlaff J, Altman DG: Preferred reporting items for systematic reviews and meta-analyses: the PRISMA statement. Ann Intern Med 2009;151:264-269, W64.

25 Jadad AR, Moore RA, Carroll D, Jenkinson C, Reynolds DJ, Gavaghan DJ, et al: Assessing the quality of reports of randomized clinical trials: is blinding necessary? Control Clin Trials $1996 ; 17: 1-12$
26 Thiel A, Hartmann A, Rubi-Fessen I, Anglade C, Kracht L, Weiduschat N, et al: Effects of noninvasive brain stimulation on language networks and recovery in early poststroke aphasia. Stroke 2013;44:2240-2246.

27 Waldowski K, Seniów J, Leśniak M, Iwański S, Członkowska A: Effect of low-frequency repetitive transcranial magnetic stimulation on naming abilities in early-stroke aphasic patients: a prospective, randomized, doubleblind sham-controlled study. ScientificWorldJournal 2012;2012:518568.

28 Kindler J, Schumacher R, Cazzoli D, Gutbrod $\mathrm{K}$, Koenig M, Nyffeler T, et al: Theta burst stimulation over the right Broca's homologue induces improvement of naming in aphasic patients. Stroke 2012;43:2175-2179.

29 Anderkova L, Rektorova I: Cognitive effects of repetitive transcranial magnetic stimulation in patients with neurodegenerative diseases - clinician's perspective. J Neurol Sci 2014;339:15-25.

30 Gow D, Rothwell J, Hobson A, Thompson D, Hamdy S: Induction of long-term plasticity in human swallowing motor cortex following repetitive cortical stimulation. Clin Neurophysiol 2004;115:1044-1051.

31 Naeser M, Martin P, Theoret H, et al: TMS suppression of right pars triangularis, but not pars opercularis, improves naming in aphasia. Brain Lang 2011;119:206-213.

32 Atkins D, Eccles M, Flottorp S, Guyatt GH, Henry D, Hill S, et al: Systems for grading the quality of evidence and the strength of recommendations I: critical appraisal of existing approaches The GRADE Working Group. BMC Health Serv Res 2004;4:38. 